\title{
Prevalence and Nature of Mental Health Problems Among Single, Homeless People in Belfast, Northern Ireland
}

\section{Sinéad McGilloway \& Michael Donnelly}

To cite this article: Sinéad McGilloway \& Michael Donnelly (2001) Prevalence and Nature of Mental Health Problems Among Single, Homeless People in Belfast, Northern Ireland, International Journal of Mental Health, 30:3, 40-49, DOI: 10.1080/00207411.2001.11449524

To link to this article: https://doi.org/10.1080/00207411.2001.11449524

Published online: 02 Sep 2015.

Submit your article to this journal $\sqsubset$

Щ Article views: 34

Q View related articles ๘

Citing articles: 1 View citing articles ๘ 
International Journal of Mental Health, Vol. 30, No. 3, Fall 2001, pp. 40-49.

(C) 2001 M.E. Sharpe, Inc. All rights reserved.

ISSN 0020-7411/2001 $\$ 9.50+0.00$.

Sinéad McGllloway and Michael Donnelly

\section{Prevalence and Nature of Mental Health Problems Among Single, Homeless People in Belfast, Northern Ireland}

There has been growing concern about the increasing numbers of homeless people with mental ill health, many of whom may be falling through the "net" of mental health services [1]. A recent large UK study [2] —which excludes Northern Ireland (NI)-provided a comprehensive picture of the prevalence of mental morbidity among homeless people. However, there is still some uncertainty about the extent and severity of mental disorders among this population. Furthermore, hostel staff in Belfast (NI) and elsewhere have expressed concerns about their capacity to provide appropriate care and support. Approximately 1 percent of the NI population $(21,000)$ were registered as "statutory homeless" (i.e., as opposed to the "hidden homeless") during 1995-96, 40 percent of whom were considered "vulnerable" (e.g., because of physical or mental disability).

The present study was undertaken to assess the prevalence and nature of mental health problems among "single," homeless adults-over 16 years of age and living alone-in all of the hostels and a small group of Bed and Breakfast (B\&B) houses in Belfast. The study was designed to: $(a)$ assess the level of functioning and dependency of residents with mental ill health (as a proxy for major mental disability); $(b)$ detect self-reported mental morbidity; and (c) identify levels of alcohol dependency and substance abuse. Mental health problems were defined

Dr. McGilloway is a lecturer in the Department of Psychology, National University of Ireland, Maynooth, County Kildare, Ireland; and Dr. Donnelly, is a reader in the Department of Epidemiology and Public Health, School of Medicine, Queen's University, Belfast, Northern Ireland.

The authors gratefully acknowledge the support of the Interagency Group on Mental Health and Homelessness, which funded this study. We also extend our thanks to Terry Bayles (South and East Belfast Trust), who collaborated on the interrater study, and to the hostel staff and their residents who agreed to participate in the research. 
broadly to include specific disorders such as schizophrenia and/or mental health difficulties perceived to be related to alcohol/substance abuse.

\section{Method}

\section{Mental health workshop}

Fifty-five "key" members of staff from each hostel and B\&B attended one of four "Mental Health Workshops" [3], after which they identified, on a "census day," all residents with a mental health problem. The workshop informed participants about the nature of mental ill health and provided training in the use of research instruments. This helped to ensure a common approach to the identification and assessment of residents.

\section{Participants, settings, and procedure}

All of the 31 hostels in Belfast were asked to participate in the study (see McGilloway and colleagues [3] for a description of hostels). However, two withdrew shortly after the study had begun, and staff in another two hostels did not consider their residents (victims of domestic violence) suitable for inclusion in the study. Six of the $18 \mathrm{~B} \& \mathrm{~B}$ houses that accommodate homeless people in Belfast were also included in the study as they provided 24-hour cover. Three social workers (SWs) and two Community Psychiatric Nurses (CPNs) participated in the mental health workshops and provided advice and guidance to staff.

A total of 401 "single homeless" people were surveyed (i.e., all those who were living in the hostels on the census day). Staff identified residents whom they considered (from hostel records and guidelines received at the workshop) to have a mental health problem (i.e., the "target" group). A one-in-five random sample was selected by the researchers from the list of remaining residents thought not to have a mental health problem. This comparison group provided an indication of the degree of accuracy with which hostel staff identified residents with mental ill health. The "target" and comparison groups were assessed using the instruments described below. A pilot study was conducted in a hostel outside Belfast.

\section{Data collection instruments}

\section{Sociodemographic questionnaire}

A sociodemographic questionnaire was completed by hostel staff in conjunction with each resident and using information from hostel records.

\section{REHAB}

The REHAB scale was used to assess levels of functioning and dependency related to major mental disability $[4,5]$. REHAB training-carried out to ensure 
standardized ratings - was provided as part of the mental health workshop. The scale is used to assess observed behavior during a one-week period.

Part One assesses "deviant behavior" (DB) and includes seven items (e.g., physical violence) scored from 0 to 2 to produce a maximum score of 14 . Scores above two indicate behavior that may require professional intervention. Part Two assesses five aspects of "general behavior" (GB) (see Table 1), covering 16 items scored from 0 to 9 to give a maximum (most deteriorated) score of 144. Cutoff scores indicate how subjects compare with a typical psychiatric- or day-hospital population. GB scores are divided, according to convention, into three bands: "potential for discharge" or "community survivors" (0-40), "moderately handicapped/ impaired" (41-64), and "severely handicapped/impaired" (65+).

\section{General Health Questionnaire (GHQ-12) and the CAGE}

Each resident completed two questionnaires. The GHQ-12 [6] is a measure of mental morbidity on which a score of more than two from a maximum of twelve indicates "caseness." The CAGE [7] is a reliable screening instrument on which respondents reply "yes" (1) or "no" (0) to four questions. A score of two or more from a maximum of four suggests potential alcohol dependency. Three questions on substance abuse were also included.

\section{Assessment of reliability and validity}

The reliability and validity of the identification and assessment procedure employed by staff were monitored by: (a) examining interrater reliability on the RE$\mathrm{HAB}$ in a small substudy involving staff from 7 hostels (analysis of 16 double (independent) ratings indicated good agreement among raters ( $r=0.80$ for total $\mathrm{DB}$ scores and $\mathrm{r}=0.89$ for total GB scores; significant at the $\mathrm{P}<0.001$ level)); and (b) analyzing various REHAB scores and other measures. This revealed significant differences in the expected direction between the "target" and comparison groups, confirming that staff members had correctly identified people with and without a mental health problem (see Table 1).

\section{Results}

\section{Sociodemographic profile}

Forty-one percent (165/401) of people were identified as having a mental health problem. The group was predominantly male (83 percent $(136 / 163)$, with an average age of 41 years. Forty percent of residents (65/163) were aged under 35, and 10 percent (all men) were aged 65 or over. Most people were homeless owing to alcohol/drug-related problems (20 percent, 32/163), parental dispute ( 11 percent, $18 / 163$ ), religious intimidation (11 percent, 18/163), or marital breakdown/dis- 
Table 1

Mean Scores Obtained by the "Problem" and Comparison Groups "Problem" group Comparison group

\begin{tabular}{lrrrrrr}
\hline Instrument & Mean & SD & Total & Mean & SD & Total \\
\hline REHAB: & & & & & & \\
& & & & & & \\
Total DB & 1.6 & 1.88 & 165 & 0.4 & 0.88 & 31 \\
Total GB & 43.5 & 25.74 & 165 & 16.5 & 17.79 & 31 \\
& & & & & & \\
Five GB dimensions: & & & & & & \\
Social activity & 19.4 & 12.18 & - & 8.3 & 9.87 & - \\
Speech skills & 3.5 & 4.14 & - & 0.9 & 2.37 & - \\
Disturbed speech & 4.7 & 4.41 & - & 1.7 & 2.44 & - \\
Self-care & 10.0 & 10.79 & - & 4.1 & 5.88 & - \\
Community skills & 7.4 & 4.59 & - & 2.3 & 3.85 & - \\
& & & & & & \\
GHQ-12 & 4.9 & 4.15 & 137 & 2.5 & 3.65 & 27 \\
CAGE & 1.9 & 1.57 & 135 & 1.3 & 1.52 & 25 \\
\hline
\end{tabular}

pute ( 8 percent, 13/163). Almost half (48 percent, 78/163) had been homeless continuously for longer than a year (see Table 2 for a profile of the comparison group).

Fifty-nine percent (96/163) of the "target" group had an "institutional" history, almost a quarter of whom (22/96) had experienced more than one "institutional" environment. In total, 33 percent $(54 / 163)$ had been in psychiatric inpatient care; 28 percent $(46 / 163)$ had been in prison; and 15 percent $(24 / 163)$ had a "care" background (e.g., foster home). No information was available foi 18 (11 percent) respondents. Only 4 percent (6/163) were homeless because of reported discharge from a psychiatric hospital.

\section{Types of mental health problem identified among the "target" group}

Hostel staff identified 37 percent (61/165) of residents as having a specific mental health problem only, although a further 27 percent (45/165) were judged to have a specific mental health problem and mental health difficulties related to the abuse of alcohol and/or drugs. A similar proportion (28 percent, 46/165) was considered to have alcohol dependency only. 
Table 2

Personal Characteristics of the "Problem" and Comparison Groups

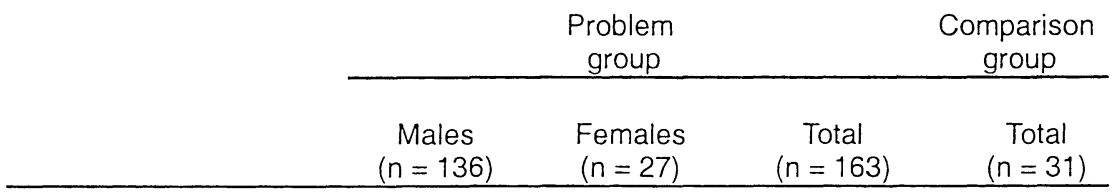

Characteristics

Number (\%) Number (\%) $\quad$ Number (\%) $\quad$ Number $(\%)$

Age:

\begin{tabular}{|c|c|c|c|c|}
\hline Mean $^{2}$ & 42 & 33 & 41 & 44 \\
\hline Standard deviation & 16.24 & 12.44 & 15.98 & 19.71 \\
\hline Range & $18-83$ & $17-59$ & $17-83$ & $17-77$ \\
\hline \multicolumn{5}{|l|}{ Marital Status: } \\
\hline Single & $89(65)$ & $15(55)$ & $104(63)$ & $17(55)$ \\
\hline $\begin{array}{l}\text { Divorced/ } \\
\text { separated }\end{array}$ & $42(31)$ & $11(41)$ & $53(32)$ & $10(32)$ \\
\hline Widowed & $4 \quad(3)$ & $1 \quad(4)$ & $5 \quad(3)$ & 1 (3) \\
\hline Not known & 1 (1) & - & $1 \quad(1)$ & $3(10)$ \\
\hline \multicolumn{5}{|c|}{$\begin{array}{l}\text { Length of time since } \\
\text { last permanent home: }\end{array}$} \\
\hline $0-6$ months $^{3}$ & $32(24)$ & $8(30)$ & $40(24)$ & $6(19)$ \\
\hline $7-12$ months & $22(16)$ & $9(33)$ & $31(19)$ & $2(6)$ \\
\hline $1-2$ years & $16(12)$ & $4(15)$ & $20(12)$ & $5(16)$ \\
\hline $3-5$ years & $21(15)$ & $3(11)$ & $24(15)$ & $5(16)$ \\
\hline Less than 5 years & $33(24)$ & 1 (4) & $34(21)$ & $10(32)$ \\
\hline Not known & $12(9)$ & $2(7)$ & $14 \quad(9)$ & $3(10)$ \\
\hline
\end{tabular}

Notes:

${ }^{1}$ The comparison group included 23 men and 8 women.

${ }^{2}$ The mean ages of the men and women in the comparison group were 48 and 34 years, respectively.

${ }^{3}$ Six members of the "problem" group (5 men and 1 woman) and 2 members of the comparison group ( 1 man and 1 woman) had been homeless for less than one month.

\section{Assessment of functioning/dependency (REHAB)}

\section{Deviant behavior}

Almost one-quarter of residents had high DB scores (above two), which suggested levels of impairment comparable with the worst 5 percent of patients in an average 
day-hospital population (Table 3). Furthermore, the mean score (Table 1) is similar to what would be expected in an average long-stay population of patients with "discharge potential" [5]. There was a significant association $\left(\chi^{2}=14.30, \mathrm{df}=4, \mathrm{P}\right.$ $<0.01$ ) between previous institutional history and DB (e.g., 30 percent [14/46] with a known criminal record were high scorers).

\section{General behavior}

The mean GB score (Table 1) indicated that, overall, the group was comparable with the worst 15 percent of patients in an average day hospital. However, half were rated as having sufficient skills to "survive" in the community with minimal or no formal support (most of whom would require day-hospital care). Almost one-third of residents had scores comparable with those of a group of "moderately impaired" psychiatric inpatients (or the worst 15 percent of day-hospital patients), and almost one in five had scores within the "severely impaired" range (see Table $3)$. There was a highly significant association $\left(\chi^{2}=25.29\right.$, $\left.\mathrm{df}=8, \mathrm{P}<0.001\right)$ between GB scores and previous institutional history. For example, 48 percent (40/ 83) of "community survivors" had been in prison or a psychiatric hospital compared with 70 percent (21/30) of the "severely impaired" group. Sixty-two percent of high DB scorers (24/39) also had either "moderately" (12) or "severely" (12) impaired GB, although there was no significant association between the two $\left(\chi^{2}=\right.$ $5.32, \mathrm{df}=2, \mathrm{P}>0.05$ ).

\section{Self-report measures}

Sixty-one percent of those who completed a GHQ-12 were psychiatric "cases" (Table 3). Although proportionately more of those scoring in the top band (9-12) were women (38 percent, 8/21) (compared with 21 percent (25/116) men), there was no significant association with $\operatorname{sex}\left(\chi^{2}=21.17, \mathrm{df}=12, \mathrm{P}<0.05\right)$. Fifty-eight percent of residents scored two or more on the CAGE (Table 3), including 79 percent (30/38) of those with mental health difficulties due to alcohol abuse. Almost one-quarter were using drugs such as marijuana (22/33), usually on a regular basis. Approximately three-quarters of this group were under 34 and included proportionately more women (38 percent, 8/21) than men (22 percent, 25/114); two-thirds were psychiatric "cases"; and over half scored two or more on the CAGE.

\section{Discussion}

This research - the first comprehensive, systematic investigation of mental health and homelessness in Ireland-was a prevalence study as opposed to a case-series study, on which many homeless surveys are based. The results are based mainly on staff assessments of functioning and dependency related to major mental disability. No information was available on diagnosis or receipt of psychiatric treat- 
Table 3

\section{Summary of Scores}

Measure and score

Number for

groupings

whom information

was available

$\%$

REHAB GB

$2-40^{1}$
$41-64$

83

50

$51-31$

$31 \quad 19$

39

24

Total completed

165

$\mathrm{GHQ}$

3-5

26

19

6-8

25

18

9-12

33

24

Total completed

137

CAGE

2

15

11

3

32

24

4

31

23

Substance abuse

33

24

Total completed

135

Note:

'Only 31 people (37\%) had "normal" to "near normal" scores.

ment. However, diagnostic techniques reveal little about the degree of disability, and severely disabled residents may also be unable or unwilling to tolerate lengthy psychiatric interviews [8].

Furthermore, hostel staff in this study were ideally placed-particularly in view of the relative stability of the homeless population in Belfast - to assess residents and to overcome the problems associated with the mistrust and suspicion commonly felt by homeless people toward unknown observers. Concerns about the ability of hostel staff to identify residents with mental health problems (i.e., when 
not using hostel records) were addressed by holding four "mental health workshops." Although it is possible that there was some bias in case ascertainment, hostel staff identified and assessed cases on the basis of $(a)$ a structured training program and $(b)$ a common set of guidelines, the implementation of which was monitored by mental health professionals. There was a high level of interrater agreement and significant differences-in the expected direction-between the REHAB scores of the "target" and comparison groups.

The prevalence rate of mental problems (41 percent) is comparable with estimates reported elsewhere [1]. However, two of the larger all-male hostels had 57 percent (17/30) and 84 percent (32/38) of mentally ill residents. Service planners and providers should target these kinds of hostels that are at risk of developing into "mini institutions" [8].

Only 4 percent in this study became homeless after leaving hospital care. This is consistent with previous local and national findings $[9,10]$ and suggests that most of those with a history of psychiatric hospitalization (33 percent) are "revolving door" patients. A large proportion had also been in prison and/or in "care" before becoming homeless. Residents with chronic mental health problems are likely, therefore, to place a considerable demand on mental health services. The high levels of DB may also pose difficulties for hostel staff and service-providers.

The strong association between REHAB scores and institutional history indicates that single homeless people have behavioral problems that may contribute to a cycle of homelessness, crime, and mental ill health. The large proportion who had previously been in prison suggests that involvement in the criminal justice system may increase the risk of housing problems [11], although the homeless mentally ill are more likely to be imprisoned than those without any mental disorder [12]. The 22 people (13 percent) who had been in prison or a psychiatric hospital and/or in "care" may merit particular attention. Furthermore, half of the residents had sufficiently poor levels of general functioning to require institutional-type care.

The GHQ results indicate, in line with research conducted elsewhere $[2,13]$, that a significant proportion of homeless people would benefit from professional mental health intervention. Although the precise association between homelessness and major mental illness remains unclear, it may be that the "stresses and strains" of becoming homeless contribute significantly to the high levels of mental morbidity in this population. The causes of homelessness may also increase significantly the risk of developing acute or long-term mental health problems [14].

Over half of the residents were judged to have alcohol-related problems, a high proportion of whom also reported "problem drinking" on the CAGE-confirming staff judgments about the nature of their mental health problems. Although these people may require less urgent or intensive psychiatric help than others, problem drinking can create management difficulties for hostel staff and tends to lead to more social and vocational impairment in homeless people than among alcoholics in the general population [15]. Moreover, drug misuse in this study may have been underestimated owing to the illegality of drugs and/or their prohibited use on hos- 
tel premises. Both alcohol and drug misuse have been shown to occur in 9 percent to 63 percent of homeless residents [1].

In this study the comorbidity of alcohol/drug-related problems and mental health difficulties may be a cause for concern and raises questions as to what type of service provision would be best suited to these people, some of whom may be resistant to psychiatric intervention. Previous research suggests that the most effective service provision comprises selective hospital admission in combination with multidisciplinary team input and case management, crisis work, or counseling [1]. Substance abuse may be viewed by mental health professionals as the primary problem in people with coexisting mental health and alcohol/drug problems [16]. Specialist multidisciplinary teams could provide valuable support to professionals in helping to reduce rejection of what are perceived to be such difficult-to-manage patients [17].

A significant proportion of single homeless people in Belfast have serious mental health problems, and many have "deviant" behavior and levels of general impairment more typical of the most severely ill patients in an average day-hospital population. The explanation for the link between poor overall functioning/dependency and homelessness is likely to be multifactorial, but may arise from an initial inability to develop adequate coping skills coupled with a constant downward drift [18]. However, it is also likely that appropriate service responses would alleviate the problems of homelessness and mental health.

The comparatively high incidence of problem drinking and, to a lesser extent, drug misuse reported here and the self-reported mental morbidity experienced by many residents raise important questions about the ability of untrained hostel workers to deal with people who require specialist supervision and support. Although it is possible that some people may be reluctant to accept mental health care owing to, for example, the severity of their problems [19], many would appear to be going undetected by providers of mental health services. Alternatively, existing care may well be inadequate. A companion paper, presented immediately following this one, describes the health and social care needs of the homeless residents in this study and indicates that, without appropriate accommodation and, among other things, assertive multidisciplinary intervention, many homeless people will remain vulnerable to the effects of mental ill health and/or crime.

\section{References}

1. Scott, J. (1993) Homelessness and mental illness. British Journal of Psychiatry, 162,314 .

2. Gill, B., Meltzer, H., Hinds, K., \& Pettigrew, M. (1996) Psychiatric morbidity among homeless people. OPCS Surveys of Psychiatric Morbidity in Great Britain, Report 7. London: HMSO.

3. McGilloway, S., Bayles, T., \& Donnelly, M. (1997) Mental health promotion and education for staff working in hostels for the homeless. In D. Trent \& C. Reed (Eds.), Promotion of mental health. Vol. 6. Aldershot: Ashgate Publishing. 
4. Baker, R., \& Hall, J.N. (1994) REHAB: Rehabilitation evaluation Hall and Baker. Aberdeen: Vine Publishing.

5. Baker, R., \& Hall, J.N. (1994) A review of the applications of the REHAB assessment system. Behavioral \& Cognitive Therapy, 22, 211.

6. Goldberg, D.P. (1978) Manual of the general health questionnaire. Windsor: NFER-Nelson.

7. Ewing, J.A., \& Rouse, B.A. (1970) Identifying the hidden alcoholic. Presented at the 29th International Congress on Alcohol and Drug Dependence. Sydney, Australia, 3 February.

8. Marshall, M., \& Gath,D.G. (1992) What happens to homeless mentally ill people? Follow-up of residents of Oxford hostels for the homeless. British Medical Journal, 304, 387.

9. Donnelly, M., McGilloway S., Mays, N., Perry, S., Knapp, M., Kavanagh, S., Beecham, J., Fenyo, A., \& Astin, J. (1994) Opening new doors: An evaluation of community care for people discharged from psychiatric and mental handicap hospitals. London: HMSO .

10. Geddes, J., Newton, R., Young, G., Bailey, S., Freeman, C., \& Priest, R. (1992) Comparison of prevalence of schizophrenia among residents of hostels for homeless people in 1966 and 1992. British Medical Journal, 308, 816.

11. Liddiard, M. (1992) Explaining youth homelessness: Issues and approaches. In P. Kennett (Ed.), New Approaches to homelessness. Working Paper 104. University of Bristol, School for Advanced Urban Studies.

12. Shanks. N.J. (1983) Medical provision for the homeless in Manchester. Journal of the Royal College of General Practitioners, 33, 40.

13. Victor, C.R. (1992) Health status of the temporarily homeless population and residents of North West Thames region. British Medical Journal, 305, 387.

14. Bines, W. (1994) The health of single homeless people: Discussion Paper 9. University of York: Center for Housing Policy.

15. Keogal, P., \& Burman, A. (1987) Alcoholism among homeless adults in the inner city of Los Angeles. Archives of General Psychiatry, 45, 1011.

16. Lart, R., \& Swyer, B. (1997) Without these walls. Health Service Journal, 2 January.

17. Timms, P.W., \& Fry, A.H. (1989) Homelessness and mental illness. Health Trends, 21,70 .

18. Craig, T., Bayliss, E., Klein, O., Manning, P., \& Reader, L. (1995) The homeless mentally ill initiative. London: Department of Health.

19. Lamb, D. (1990) Will we save the homeless mentally ill? American Journal of Psychiatry, 147, 649. 